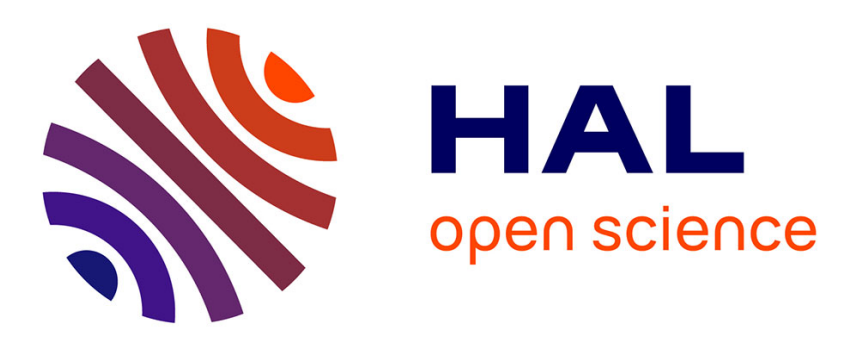

\title{
A Conceptual Proposal for Responsible Innovation
}

Thais Assis de Souza, Rodrigo Marçal Gandia, Bruna Habib Cavazza, André Grützmann, Isabelle Nicolaï

\section{To cite this version:}

Thais Assis de Souza, Rodrigo Marçal Gandia, Bruna Habib Cavazza, André Grützmann, Isabelle Nicolaï. A Conceptual Proposal for Responsible Innovation. EGOVIS 2020, Sep 2020, Bratislava, Slovakia. pp.49 - 63, 10.1007/978-3-030-58957-8_4 . hal-03014720

\section{HAL Id: hal-03014720 \\ https://hal-centralesupelec.archives-ouvertes.fr/hal-03014720}

Submitted on 19 Nov 2020

HAL is a multi-disciplinary open access archive for the deposit and dissemination of scientific research documents, whether they are published or not. The documents may come from teaching and research institutions in France or abroad, or from public or private research centers.
L'archive ouverte pluridisciplinaire HAL, est destinée au dépôt et à la diffusion de documents scientifiques de niveau recherche, publiés ou non, émanant des établissements d'enseignement et de recherche français ou étrangers, des laboratoires publics ou privés. 


\title{
A Conceptual Proposal for Responsible Innovation
}

\author{
Thais Assis de Souza ${ }^{1,2(\bowtie)}\left(\mathbb{D}\right.$, Rodrigo Marçal Gandia ${ }^{1,2}$ (D), \\ Bruna Habib Cavazza $^{1}$ (D), André Grutzmann ${ }^{1}$ (D), and Isabelle Nicolaï ${ }^{2}$ (D) \\ ${ }^{1}$ Federal University of Lavras, Lavras, Minas Gerais 37200-000, Brazil \\ assis.sthais@gmail.com \\ 2 CentraleSupélec/Université Paris-Saclay, LGI - Laboratoire Génie Industriel, \\ Gif-sur-Yvette 91190, France
}

\begin{abstract}
The concept of Responsible Innovation holds that any innovation should take into account the balance of economic, ethical, social and sustainable aspects throughout the entire project in a manner that shows care for the future being constructed. However, as this concept is recent, originates in the context of the European Union and addresses issues of the Global North, critics have called for improvements in the way the concept is formulated. This article aims to establish a broader perspective to support the development of the concept of Responsible Innovation, which means discussing its main premises to highlight its critical aspects related to contextual terms, supporting a view to adapt it for use in different countries under various requirements and circumstances, thus facilitating its implementation on the path to innovation. Thus, an integrative review was developed. From an analysis of articles chosen based on research criteria, a useful theoretical framework was formed to fill the gaps in Responsible Innovation, comparing its perspectives to a traditional innovation, establishing a concept capable of yielding the expected benefits.
\end{abstract}

Keywords: Responsible innovation · Integrative review · Theoretical framework

\section{Introduction}

Innovation, as a concept, brings wide possibilities to delivering something substantially new, which generates some kind of value. The general premise is the combination of intellectual and practical creativity to bring about changes in what is known in the world. This transformation is therefore considered a creator of the future and can be conceived from incremental improvements to radical changes [2,9].

Highlighting the change aspect promoted by an innovation, Jonas [10] discusses the "principle of responsibility" as an appropriate alternative for addressing technological impacts by indicating that modern technology must consider the effects of its action to influence human conditions; in this sense, action must be reflected and prudent.

The notion of responsibility has always been present in research and innovation practices, although this notion can be different in terms of time and place [24]. However, 
the topic of Responsible Innovation (RI) is emergent and starts from the intention to create an approach with the purpose of reducing the uncertainties and ambiguities of an innovation while focusing on ethics, sustainability and social aspects $[18,24]$. In this sense, RI is related to the intention to take care of the future through the management of innovation in the present [24].

Considering the European origin of the concept of Responsible Innovation, a forum was held in March 2014 in Campinas (Brazilian city), where Brazilian and UK researchers debated RI as a treaty in which there are specific considerations of realities in developed countries. For the researchers, it is necessary that the concept of RI be placed in debates on urban and economic development, institutional reforms, capacity building, transitions and social responsibility. To do so, it is essential to consider cultural, social and political aspects [13].

On the other hand, there are still criticisms and discussions about the concept of RI related to a lack of amplitude [21], a lack of practical indication [21, 32] and strong relations with political issues of the Global North $[8,24]$, which hinder its institutionalization [4].

In this sense, we understand the importance of considering the specificity of cultural and institutional contexts with respect to RI. Thus, it is crucial to seek a better conceptualization of RI so that its premises provide more beneficial results in the future. For Wodzisz [32], to discriminate against irresponsible innovations (referred to as traditional innovation in this work) is to avoid unnecessary effort in improving the impact of innovation, thereby simplifying the consideration of aspects of responsibility from the beginning of a project.

Given the aforementioned, this work is guided by the following questions: How is the field of studies in Responsible Innovation characterized? What are the approaches established by the concept of Responsible Innovation and its main characteristics? How can the concept of Responsible Innovation be configured to the detriment of a traditional innovation approach?

In this way, this work aims to identify characteristics and precepts established by the concept of Responsible Innovation and to discuss the exposed distinctions between responsible and traditional approaches to contribute to its applicability and construction of the state of the art.

This study can also be justified because it provides opportunities for academic and practical advances given that the theoretical field permeating RI is still incipient and under construction. Moreover, a bird's eye view on the applicability of a conceptualization and operationalization of Responsible Innovation allows it to be applied in different countries and based on different needs and realities facilitating its application in the innovation journey.

\section{Responsible Innovation}

Innovation, which is able to take many different forms, is a concept that deserves considerable exploration. In general, one can consider four main dimensions: product innovation, process innovation, position innovation, and paradigm innovation [7].

It has been said that innovation represents a challenge in that it is a moving target. The challenge is related to the finding that in dynamic environments, constant changes 
present new threats, new technologies, new markets and new regulatory frameworks. Thus, companies are concerned with ensuring their long-term survival [2].

In terms of results, it is not possible to argue that all innovations are essentially good, even if they propose to offer benefits. A well-known example is DDT, which was initially acclaimed as an innovation that would revolutionize the field of pesticides; however, significant negative impacts later came to light. Other negative impacts include nuclear energy and the development of "wonder" drugs. These considerations show the need to consider innovation options in a way that ensures an approach characterized by Responsible Innovation [2].

Before conceptualizing Responsible Innovation (RI), one must ask a plausible and necessary question: What qualifies as responsible? In the conceptual basis of Responsible Innovation, responsibility refers to the future that the innovation intends to create. Due to the wide range of possibilities for innovation and its goals, the nature of responsibility presents conceptual and practical difficulties [9].

$\mathrm{RI}$ is an emerging discourse through which various authors seek to reduce the uncertainties and ambiguities of an innovation through the concise construction of a promising framework [18, 24].

RI originates in the broader idea of Responsible Research and Innovation (RRI), which became an important expression in European political discourse because of its relation to future issues addressed in the European Union program "Horizon 2020," specifically with regard to the subject of research and innovation [11, 29]. RRI translates into a discourse containing a number of ideas that will most likely influence the way we will assess issues related to technological research and innovation in the future. As Stahl et al. [21] note, responsible research and innovation concept can be viewed as an umbrella used that includes orientation aspects to develop innovation, science, research and technology that turn into positive, desirable and socially acceptable outcomes.

In conceptual terms, there is no commonly held definition for RI, nor is there agreement on the best approach to implement it [29]. Owen, Macnaghten and Stilgoe [15] highlight some criticisms that consider RRI ambiguous in terms of its motivation, it needs a theoretical conceptualization more established and there is a lack of orientation to its translation into practice. Von Schomberg [28] considers it a process that focuses on transparency and the interaction of innovative social actors who bear in mind the mutual responsibility, acceptability, sustainability and social suitability of the process and the results of an innovation and its products.

Stahl et al. [22] discuss a concept of RI that focuses on socially desirable results. Owen et al. [16] highlight the collective and the importance of a responsive administration with a commitment to the present and awareness of the future. According to Pavie and Carthy [19], RI is the development of new products and services that combine growth, performance and responsibility. Blok and Lemmens [3] describe RI as a new approach to innovation.

According to Koops [11], the roots of RI can be found, separately and in combination, in science, technology and social studies along lines such as technological assessment and value-sensitive design, applied ethics, and governance and regulation studies. Thus, RI seeks to bring together a variety of ideas and traditions, considering interactions in 
the context of a complex process and constituting a broad and relevant approach that is applicable to innovations in institutions, social practices, regulations and technology.

\section{Methodology}

This study undertakes an integrative review of the literature on Responsible Innovation, specifically aiming to describe the field of RI research in management and business, identify specific central concepts, summarize the evidence found, and highlight relevant aspects that can guide a concept of RI. Figure 1 shows the study's methodological design.

An integrative review is useful to review the empirical and theoretical literature, as well as present the state of the art, for the purpose of developing an analysis of the results and summarizing contributions in an integrated manner [30].

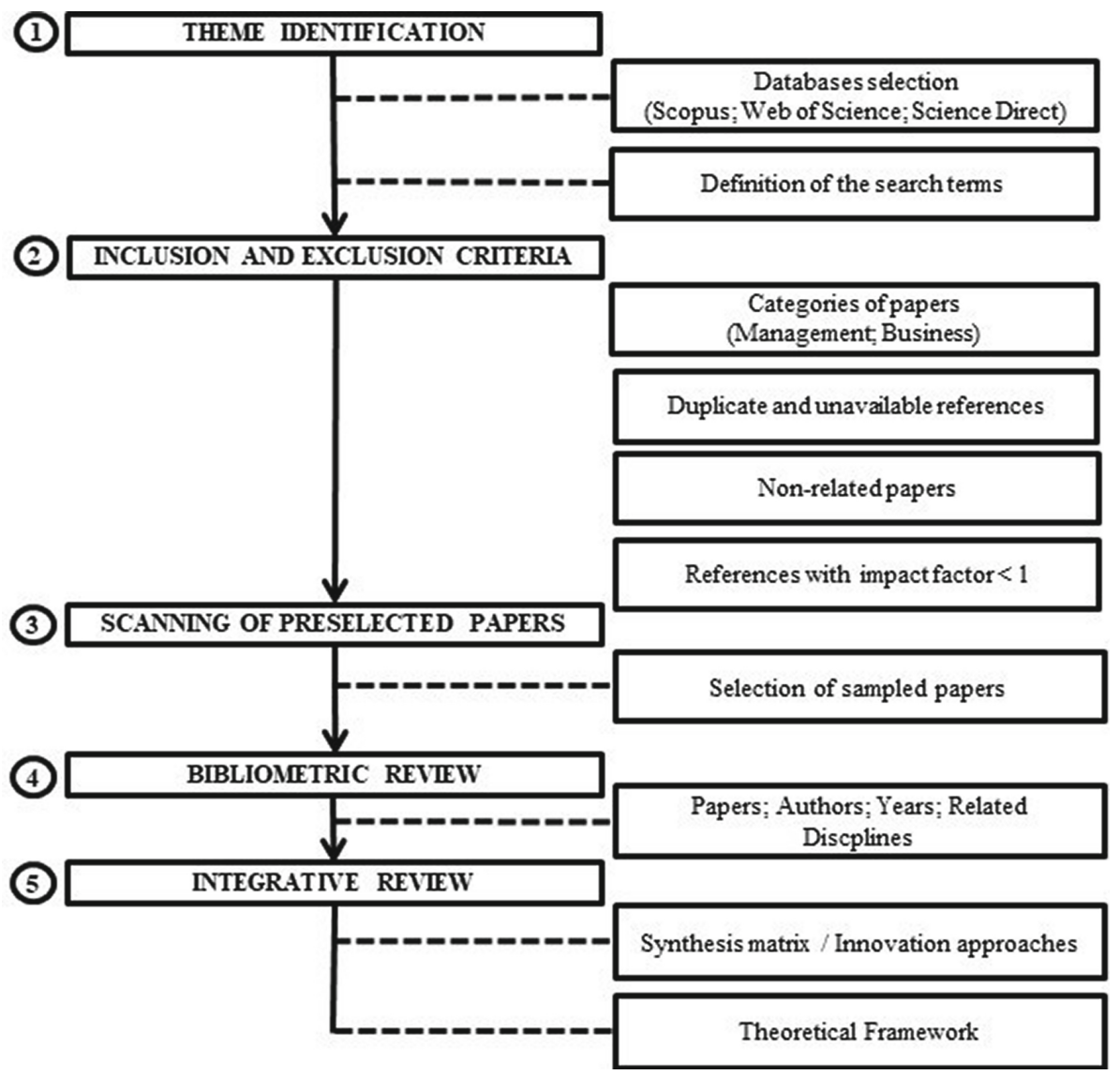

Fig. 1. Study design

Each methodological step developed is described below: 
- Stage 1 - Theme identification. A search for articles was conducted in the Scopus, Web of Science (WoS) and Science Direct (SD) databases. The search covered all years. The search term was "responsible_innovation" with the underline Boolean operator and quotation marks to return results with this exact term. In the Scopus and Web of Science databases, the search was conducted in the "title" and "topic" fields, including abstracts and keywords. Since this option was not available in the Science Direct database, the search was conducted in all fields. The search found 351 articles in Scopus, 234 in WoS and 67 in Science Direct.

- Stage 2 - Inclusion and exclusion criteria. The first criterion was that the articles must be in English. In the Science Direct and Scopus databases, the search looked for articles in the business, management and accounting fields. In the WoS database, articles were sought in the fields of economics, business and management. The first filter returned 30 articles on the Web of Science and 105 in Scopus; since Science Direct did not offer an English language filter, all 67 articles from that database remained.

Tsujimoto et al. [25] applied a classification criterion to identify the most relevant journals in the field studied. Along these lines, an impact factor analysis (InCites) considered only journals with an impact factor greater than 1. Based on this and the other criteria defined for this study, the search excluded 76 articles found in Scopus, 24 articles in Science Direct and nine on the WoS. Another 33 studies were excluded because they were duplicates, and the titles and abstracts of the remaining 70 articles were then read to determine their relevance to this study. This phase excluded 52 articles.

- Stage 3 - Scanning of preselected papers: After step 2, we ended up with 18 papers for research and analysis. Those papers were preselected for in-depth reading and analysis. It is worth noting that we used peer review to reduce bias in interpretation.

- Stage 4-Bibliometric review: To obtain a general overview of the field of Responsible Innovation, the publication years, primary authors and disciplines were identified.

- Stage 5 - Integrative review: For the purpose of establishing a broader conceptualization for operationalizing RI, an effort was made to identify aspects of its premises and conceptual elements. To this end, articles were placed on a synthesis matrix to organize them by topic: original basis, publication journal, impact factor, author, year, related country, abstract, keywords, research question, objectives, main RI concepts, theoretical and practical background, methodology, main contribution, specific details, gaps for future research, limitations and general observations. Based on the analysis of the synthesis matrix and the concepts and treatment of RI covered in the selected articles, this review highlights the considered approaches to innovation, the main concepts of RI, the main criticisms, and the related theories and practical approaches; it also presents a theoretical framework covering the main concepts and aspects discussed.

\section{Analysis and Discussion}

Beginning in 2010, discussion in the European Commission grew around the concept of the responsibility of science. A workshop in Brussels in May 2011 gave rise to the first public statements about RRI. This initially very broad concept was based on premises 
that focused on science and its relationship with society, treating risk management as the dominant paradigm [15].

Still in 2011, the term 'Responsible Innovation' (RI) gained ground in the discussion due to discomfort with the concept of RRI rooted in the European Union and science. The aim was therefore to question the public value of science and address the impact of research and open space for public participation in creating socially desirable innovation, which came to mean "innovation management" rather than "risk management" [15].

\subsection{Evolution of Publications and Overview of Responsible Innovation}

To provide a better understanding of the studies and movement of the field, Fig. 2 shows the evolution of publications over time. The sample consisted of studies from 2009 to 2018, with 2018 accounting for the largest number of publications (five). This evolution demonstrates and reinforces the overview of the initial discussions about RI and its status as an emerging field.

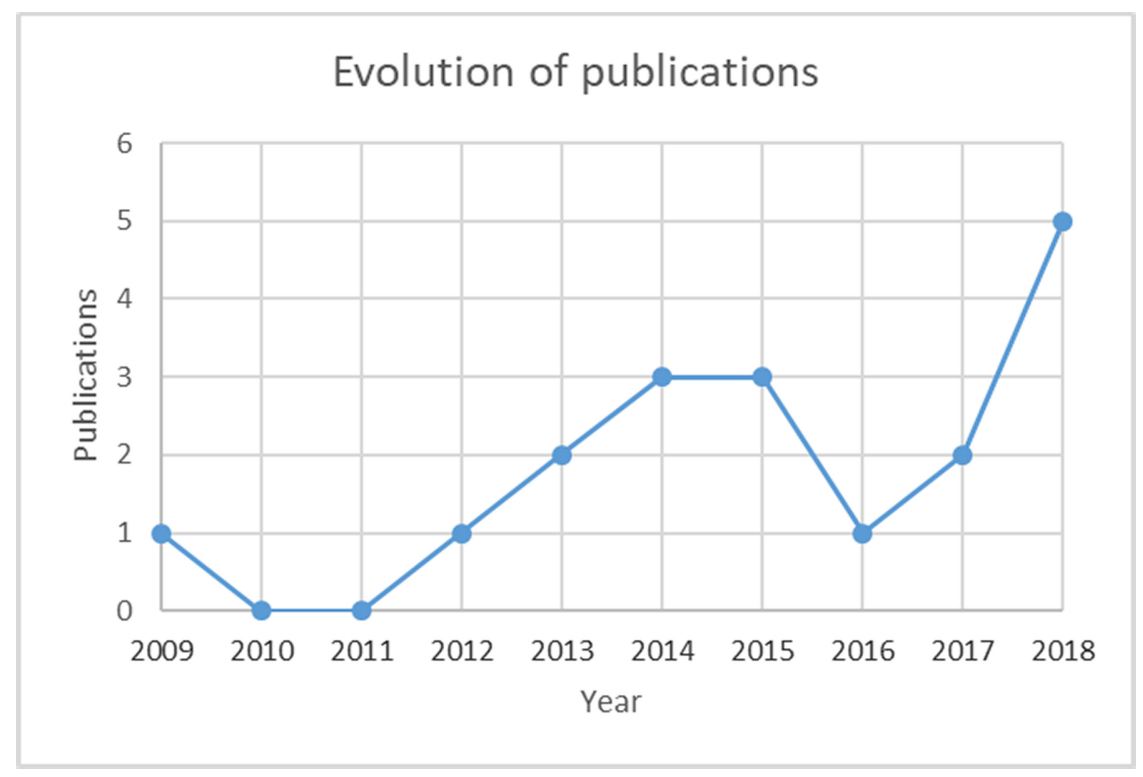

Fig. 2. Evolution of publications

Several authors stand out as having multiple works on this list; Jack Stilgoe, Richard Owen, Phil Macnaghten, Arnim Wiek, Rider W. Foley and Bernd Carsten Stahl account for two publications each. With regard to the related discipline, Fig. 3 shows the topics discussed in the sample of articles. 


\title{
Related Disciplines
}

\author{
- Nanotechnology \\ - Geoengineering \\ - Robotics \\ - Spin off \\ घ Sustainable development \\ - Neuroimaging \\ - Bioenergy \\ - Innovation Policy \\ - Automated vehicles \\ Artificial intelligence \\ $\backsim$ Speech analysis \\ = C, T \& I policy
}

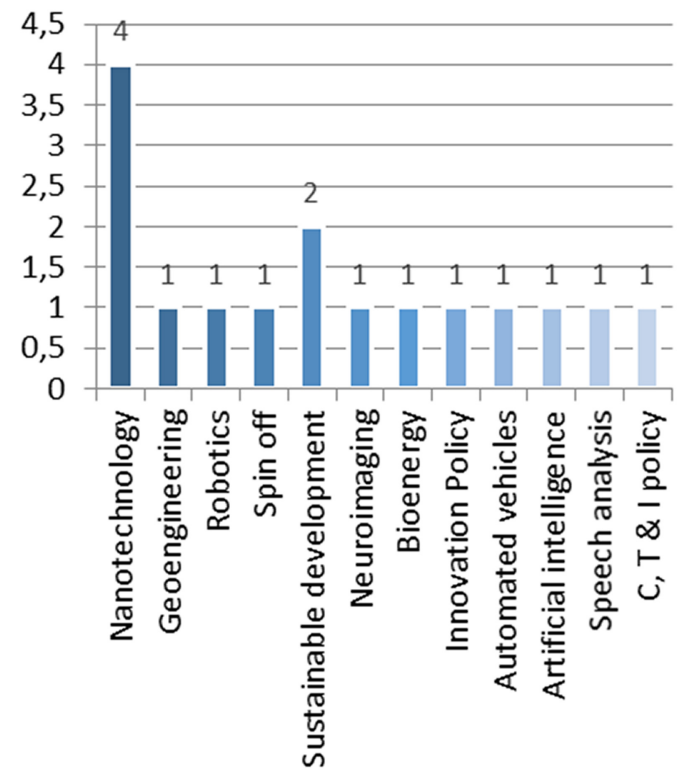

Fig. 3. Related disciplines.

Nanotechnology was cited in four articles as a practical example of innovation. On this point, it is worth noting that according to Genus and Iskandarova [8], empirical research on RI initially focused on nanotechnology, biomedical technologies, geoengineering and information technologies, and the emphasis in these articles underscores that nanotechnology in particular is widely considered in recent publications to present great challenges for science, technology and innovation (ST\&I) policies and to be one of the sources of discussion about RI $[4,6,17]$.

\subsection{Approaches to Innovation}

It is worth highlighting the conceptual approaches to "innovation" discussed. With regard to typologies, Meissner, Polt and Vonortas [14] discuss traditional types of innovation as being product innovation, process innovation, marketing innovation and organizational innovation. According to Wodzisz [32], one should consider innovations as being "already existing," "undergoing implementation" and "to be implemented in the future."

According to Legault, Verchère and Patenaude [12], innovation is the result of supply and demand, is not limited to production components and needs to be analyzed based on its impacts on cultures and societies. Thus, innovation can be seen as a complex, collective and dynamic process [4, 15, 24]. Owen, Macnaghten and Stilgoe [15] add that based on its collective character, innovation can shape the future. 
This collective feature of innovation can be explained by considering that innovation is linked to socioeconomic, environmental, health and safety factors and that to provide benefits, these factors should be seen as interrelated integrating factors [14]. Along similar lines, Arentshorst et al. [1] emphasize that innovation depends on interrelated dynamics and mechanisms such as demand, networks and technologies.

Robinson [20] suggests a metaphor for innovation as a journey involving actors, artifacts and infrastructure in a dynamic process of co-development. Underscoring that innovation is much more than technology and that the value chain of innovation is marked by nonlinear dynamics, Meissner, Polt and Vonortas [14] emphasize that other resources are essential to determining an innovation's adoption and survival in the marketplace, indicating a new direction for the mission.

In this sense, Shortall, Raman and Millar [23] highlight that innovation can take forms other than an industrial focus, but it is important to keep in mind that quality must be maintained. Wodzisz [32] discuss the importance of developing innovations to improve conditions without affecting people and the planet, thus following a logic of "doing good."

Foley and Wiek [6] believe that innovations can have long-range impacts and become global phenomena. Along similar lines, Owen, Macnaghten and Stilgoe [15] emphasize that being responsible in terms of innovation is itself innovative and has a collective aspect.

\subsection{Concepts and Approaches of Responsible Innovation}

Analysis of the articles showed that four authors are key to shaping the concept of RI: Von Schomberg, Stilgoe, Macnaghten and Owen. Of the 18 articles selected, 10 cite or refer to these authors.

Von Schomberg is generally associated with the initial concept of RRI, as he was a member of the European Commission [21, 32]. The articles that cite the works of Stilgoe, Macnaghten and Owen discuss a conceptual broadening that extends the focus of RRI, presenting RI as concept that goes beyond science and the political environment of the European Union. It is worth noting that these authors sought to complement and broaden von Schomberg's initial concept, proposing a definition based on a prospective notion of responsibility based on four dimensions: anticipation, reflexivity, inclusion and responsiveness [24].

Due to its emerging nature, the concept of RI has been criticized for its close association with the European Union and the Global North in general [8, 24], as well as for the vague nature of the concept [21] and its lack of practical orientation [21], all of which makes it difficult to institutionalize [4].

The point about the concept's geographically limited scope can be seen in the articles chosen for analysis, which considered only the context of developed countries, or, as they are known in the literature, countries of the Global North [8]. The selected articles addressed regions in different ways: two about the European Union, five about the United Kingdom, two about the United States, one about Norway, Holland, and Canada, and one about OECD member countries.

A variety of theories and practical approaches were related to RI, as displayed in Table 1. 
Table 1. Practical approaches related to Responsible Innovation

\begin{tabular}{l|l}
\hline Approach related to RI & Authors cited \\
\hline Value-sensitive design (VSD) & {$[5,12]$} \\
\hline Corporate social responsibility & {$[12,27]$} \\
\hline Constructive technology assessment (CTA) & {$[12,15,20]$} \\
\hline Technology assessment (TA) & {$[5,8,20,24,31]$} \\
\hline Scenarios & {$[6,24]$} \\
\hline Sociotechnical integration research (STIR) & {$[5,24,31]$} \\
\hline
\end{tabular}

It is worth noting that [24] suggest techniques and approaches to each dimension of the framework they propose (anticipation, reflexivity, inclusion and responsiveness).

\subsection{Integrative Review and Theoretical Framework}

Analysis of the articles showed that four authors are key to shaping the concept of RI: Von Schomberg, Stilgoe, Macnaghten and Owen. Of the 18 articles selected, 10 cite or refer to these authors.

According to Von Schomberg [29], Irresponsible Innovation is characterized by the intentions and actions of innovation that focus on technology push and policy pull, neglecting ethical aspects, foresight and caution. To fend off criticism about a classification that might be seen as pejorative, based on Von Schomberg [29], Traditional Innovation will be treated here as a type of innovation that has not yet subscribed to the premises of RI.

Based on the concepts and treatment highlighted by the articles selected for review, Responsible Innovation, as opposed to traditional innovation, is related to ethics: the lack of separation between technical and nontechnical aspects; the relationship between economic, social and environmental goals; collective values; integrative propositions; intentions for the right intergenerational impacts; innovation based on quality, security and well-being; development based on constructive dialogue with stakeholders; and attention to the country/context/domain as part of the innovative process.

A theoretical framework was therefore developed (Fig. 4) to detail the concept of RI based on the constitutive elements found in the integrative review of the literature. It is emphasized that this framework is also based on the treatment of Irresponsible Innovation highlighted by Von Schomberg [29], which is treated here as Traditional Innovation.

First, it is emphasized that innovations are distinguished by management. Responsible Innovation is considered the management of innovation, dealing with anticipation, reflexivity, inclusion and responsiveness; traditional innovation focuses on risk management in economic terms.

Responsible innovation is distinguished from traditional innovation by its premises, development interests and impacts. It starts with a project that is developed by a dynamic and nonlinear process of innovation until it reaches the market, society and 


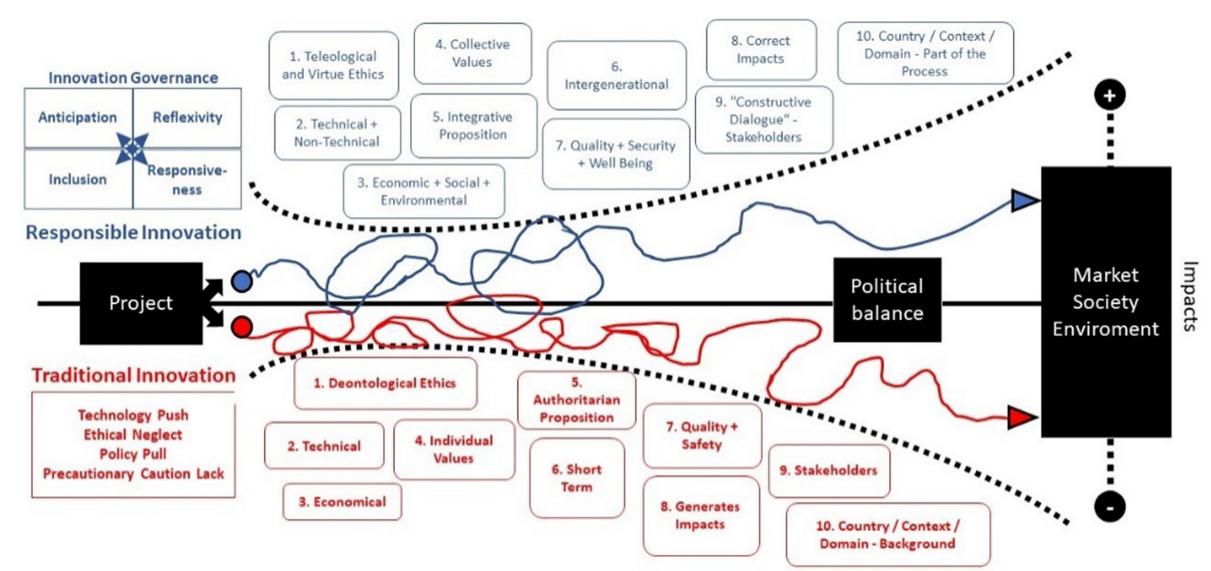

Fig. 4. Theoretical framework

the environment. It is argued that traditional innovation has a greater tendency to produce negative impacts. Responsible innovation, on the other hand, leads to more positive impacts because of its more social, ethical, sustainable and forward-looking management. However, it is not argued here that RI produces only positive impacts.

Depending on the innovation project, the path taken differs as to the premises. The nonlinearity of the innovation journey is shown using red and blue lines. It cannot be said that responsible premises facilitate the development of a project, but we state that the inclusion of elements of responsibility from the very beginning of the conception reduces the potential for problems. This is mainly due to the multidisciplinary nature of the stakeholders (inclusion), who provide a variety of perspectives on the same topic, and because they focus on reducing future uncertainties (anticipation), considering limits, barriers and conceptions (reflexivity), and paying attention to public values to improve their ability to respond to potential impacts (responsiveness).

The literature has noted the importance of political action to promote a balance between traditional and responsible innovation. This political balance can be seen as an action that values reflection, deliberation and democracy, seeking to guide responsible actions and programs without limiting the range of innovation [4, 8, 14, 23]. Policymakers take on the role of orchestrating relationships among stakeholders, focusing on a common language, promoting new initiatives and regulating the existing initiatives without taking a heavy-handed approach [14, 27].

Responsible Innovation is a meta-responsibility [21]. There is a focus on specific issues of responsibility, such as ethics [12, 21], social acceptance [5] or sustainability $[6,23,26,27,31,32]$. The question thus arises: To be considered responsible, can an innovation develop aspects separately, or must it be a complete conceptual package?

We will use the term Pure Responsible Innovation to refer to an innovation that contains all the premises of RI, without any aspect or feature of Traditional Innovation. However, we argue that an innovation does not need to be pure to be responsible. The purpose of this premise is that it is necessary to avoid the utopia of a Pure RI, as a variety of 
contextual obstacles can interfere with a smooth journey for RI. Considering the circumstances of the Global South (underdeveloped or emerging countries), some innovations may have more 'impurities'. However, recognizing barriers is already a responsible action, and it is imperative to make an effort to develop an innovation that does good and seeks to minimize negative impacts and maximize positive ones, discussing uncertainties to clarify them and benefit the environment, the market and society. An innovation can therefore be considered responsible even if it contains aspects of traditional innovation, and vice versa.

It is therefore argued that a project can overcome the dichotomy between responsible and traditional innovation along the road to innovation. As innovation is a process that takes place under specific circumstances, a responsible project can show traces of traditional innovation, such as focusing on technology push, being highly dependent on policy pull or focusing on economic and commercial goals.

RI goes beyond regulation and institutionalization by considering contextual and disciplinary differences, focusing its action on public values [5, 15, 24, 32]. Working with transparency, openness, inclusion and dialogue, an interdisciplinary effort focuses on processes rather than solely on results and looks at risks from a variety of perspectives, building a future of co-development. It is therefore necessary to pay attention to flows, links, political environments, infrastructure, markets, diversity, culture, barriers and limitations, making constructive interventions and taking into account the logic of cause and effect and the uncertain scale of an innovation's impact.

Pandza and Ellwood [17] emphasize that RI is predominantly tied to deontological and teleological ethics, often paying less attention to ethics as a virtue. Deontological ethics relates innovation to rules, norms and principles, making it easier to ensure responsibility. From a teleological perspective, innovation based on the understanding of its agents concentrates only on consequences. However, given the intrinsic uncertainty of an innovation's journey and the limitations of regulatory structures and risk management techniques, it is necessary to take a further step toward ethics based on virtuous actors. Thus, the ethics of virtue emphasize that motivation must be based on contributing to the world through innovation. This treatment highlights the importance of including stakeholders in every step of the project. Based on these considerations, it is suggested that we need to consider the consequences and rely on virtuous agents so that RI will therefore be responsible based on teleological and virtuous ethics.

In short, it is argued that we must create a responsible ecosystem. This argument is based on contextual specifics, the particulars of the practical fields, and a recognition of the importance of ethics in a scenario of coexisting factors.

\section{Conclusions}

According to Koops [11], responsibility in the concept of Responsible Innovation refers to ethical acceptance with regard to sustainability and suitability with regard to social questions so that the innovation's objectives are careful about the future, considering and balancing economic, sociocultural and environmental factors. In short, the emphasis is on including ethical and social values in the innovation process. 
To understand the concept of Responsible Innovation (RI), we extend an invitation to reflection, as we believe it is necessary to structure the innovation journey around central questions: What will be created? What will be the results and implications of this innovation? [6]. What future do we want for ourselves and for future generations? [15]. These questions indicate the main premises of RI.

To understand how the concept of Responsible Innovation may prevail over the Traditional Innovation approach, a theoretical framework was developed based on the analyses derived from the integrative review of the literature on RI, Irresponsible Innovation [29], and the criticism raised about the concept of RI.

Based on this framework, it is suggested that the standard for innovation be reflection and ethics based on teleology and virtues. In this way, recognizing that the future is built in the present, the focus turns to impacts, and it is possible to develop innovation that serves as the engine of growth and adds socioeconomic and environmental value to society, the market and the environment.

The following reflective question was thus posed: To be considered responsible, can an innovation develop aspects separately, or must it be a complete conceptual package? It is argued that the framework is not a model, but a recommendation for the best use of the Responsible Innovation approach. This is done by proposing the concept of Pure Responsible Innovation (Pure RI), which is an innovation characterized exclusively by the incorporation of all the premises of RI. However, considering the contextual factors and other characteristics of a country, it is understood that an innovation does not necessarily need to be pure to be responsible. It is argued that the very recognition of barriers is a responsible act, which maximizes the innovation's responsibility by aligning it with the effort to do good and seeking to minimize negative effects.

This study presents important contributions in that it develops a concept that includes not only the "p's" of technological innovation (product, patent, production, profit, pioneering) but also the "p's" of Responsible Innovation: people and planet. It is hoped that this article will contribute to academic progress, a general overview of the state of the art on the topic and practical treatments, as the theoretical field around RI is still being developed.

It is noted that the use of the impact factor as a filter in the selection of articles may have limited this study. However, this is a limitation designed to ensure that the study works with the most influential articles in the literature [25].

It is suggested that future research include a deeper analysis of each of the characteristics of Traditional and Pure Responsible Innovation, as well as the application of the theoretical framework in a practical context, thus proposing the applicability of Responsible Innovation with nonpure characteristics. Moreover, future studies can highlight the roles of the stakeholders involved in RI in a manner that addresses the identified gaps, such as criticism of the lack of practical approaches to the concept.

Acknowledgments. This work is supported by the "ADI 2019" project funded by the IDEX Paris-Saclay, ANR-11-IDEX-0003-02. 


\section{References}

1. Arentshorst, M.E., Buning, T.C., Boon, W.P., Broerse, J.E.: Prospecting responsible technology paths: management options for an appropriate societal embedding of medical neuroimaging. Sci. Public Policy 42(6), 775-788 (2015). https://doi.org/10.1093/scipol/ scv004

2. Bessant, J.: Innovation in the twenty-first century. In: Owen, R., Bessant, J., Heintz, M. (eds.) Responsible Innovation: Managing the Responsible Emergence of Science and Innovation in Society, pp. 01-26. Wiley, New York (2013). https://doi.org/10.1002/9781118551424

3. Blok, V., Lemmens, P.: The emerging concept of responsible innovation. three reasons why it is questionable and calls for a radical transformation of the concept of innovation. In: Koops, B.J., Oosterlaken, I., Romijn, H., Swierstra, T., van den Hoven, J. (eds.) Responsible Innovation 2, pp. 19-35. Springer, Cham (2015). https://doi.org/10.1007/978-3-319-17308-5_2

4. Flink, T., Kaldewey, D.: The new production of legitimacy: STI policy discourses beyond the contract metaphor. Res. Policy 47(1), 14-22 (2018). https://doi.org/10.1016/j.respol.2017. 09.008

5. Flipse, S.M., Puylaert, S.: Organizing a collaborative development of technological design requirements using a constructive dialogue on value profiles: a case in automated vehicle development. Sci. Eng. Ethics 24(1), 49-72 (2018). https://doi.org/10.1007/s11948-0179877-3

6. Foley, R.W., Wiek, A.: Scenarios of nanotechnology innovation vis-à-vis sustainability challenges. Futures 64, 1-14 (2014). https://doi.org/10.1016/j.futures.2014.09.005

7. Francis, D., Bessant, J.: Targeting innovation and implications for capability development. Technovation 25(3), 171-183 (2005). https://doi.org/10.1016/j.technovation.2004.03.004

8. Genus, A., Iskandarova, M.: Responsible innovation: its institutionalisation and a critique. Technol. Forecast. Soc. Chang. 128, 1-9 (2018). https://doi.org/10.1016/j.techfore.2017. 09.029

9. Grinbaum, A., Groves, C.: What is "responsible" about responsible innovation? Understanding the ethical issues In: Owen, R., J. Bessant and M. Heintz (eds.): Responsible Innovation: Managing the Responsible Emergence of Science and Innovation in Society, pp. 119-142. Wiley, New York (2013). https://doi.org/10.1002/9781118551424

10. Jonas, H.: Toward a philosophy of technology. Hastings Cent. Rep. 9(1), 34-43 (1979). https:// doi.org/10.2307/3561700

11. Koops, B.-J.: The concepts, approaches, and applications of responsible innovation. In: Koops, B.-J., Oosterlaken, I., Romijn, H., Swierstra, T., van den Hoven, J. (eds.) Responsible Innovation 2, pp. 1-15. Springer, Cham (2015). https://doi.org/10.1007/978-3-319-173 08-5_1

12. Legault, G.A., Verchère, C., Patenaude, J.: Support for the development of technological innovations: promoting responsible social uses. Sci. Eng. Ethics 24(2), 529-549 (2018). https:// doi.org/10.1007/s11948-017-9911-5

13. Macnaghten, P., et al.: Inovação responsável através de fronteiras: tensões, paradoxos e possibilidades. Teoria \& Pesquisa: Revista de Ciência Política 24(2), 18-24 (2015). https://doi. org/10.4322/tp. 24210

14. Meissner, D., Polt, W., Vonortas, N.S.: Towards a broad understanding of innovation and its importance for innovation policy. J. Technol. Transf. 42(5), 1184-1211 (2017). https://doi. org/10.1007/s10961-016-9485-4

15. Owen, R., Macnaghten, P., Stilgoe, J.: Responsible research and innovation: from science in society to science for society, with society. Sci. Public Policy 39(6), 751-760 (2012). https:// doi.org/10.1093/scipol/scs093 
16. Owen, R., Stilgoe, J., Macnaghten, P., Gorman, M., Fisher, E., Guston, D.: A framework for responsible innovation. In: Owen, R., Bessant, J., Heintz, M. (eds.) Responsible Innovation: Managing the Responsible Emergence of Science and Innovation in Society, pp. 27-50. Wiley, New York (2013). https://doi.org/10.1002/9781118551424

17. Pandza, K., Ellwood, P.: Strategic and ethical foundations for responsible innovation. Res. Policy 42(5), 1112-1125 (2013). https://doi.org/10.1016/j.respol.2013.02.007

18. Paredes-Frigolett, H., Gomes, L.F.A.M., Pereira, J.: Governance of responsible research and innovation: an agent-based model approach. Procedia Comput. Sci. 55, 912-921 (2015). https://doi.org/10.1016/j.procs.2015.07.113

19. Pavie, X., Carthy, D.: Leveraging uncertainty: a practical approach to the integration of responsible innovation through design thinking. Procedia Soc. Behav. Sci. 213, 1040-1049 (2015). https://doi.org/10.1016/j.sbspro.2015.11.523

20. Robinson, D.K.R.: Co-evolutionary scenarios: an application to prospecting futures of the responsible development of nanotechnology. Technol. Forecast. Soc. Chang. 76(9), 12221239 (2009). https://doi.org/10.1016/j.techfore.2009.07.015

21. Stahl, B.C., McBride, N., Wakunuma, K., Flick, C.: The empathic care robot: a prototype of responsible research and innovation. Technol. Forecast. Soc. Chang. 84, 74-85 (2014). https://doi.org/10.1016/j.techfore.2013.08.001

22. Stahl, B.C., Eden, G., Flick, C., Jirotka, M., Nguyen, Quang A., Timmermans, J.: The observatory for responsible research and innovation in ICT: identifying problems and sharing good practice. In: Koops, B.-J., Oosterlaken, I., Romijn, H., Swierstra, T., van den Hoven, J. (eds.) Responsible Innovation 2, pp. 105-120. Springer, Cham (2015). https://doi.org/10.1007/9783-319-17308-5_6

23. Shortall, O.K., Raman, S., Millar, K.: Are plants the new oil? Responsible innovation, biorefining and multipurpose agriculture. Energy Policy 86, 360-368 (2015). https://doi.org/10. 1016/j.enpol.2015.07.011

24. Stilgoe, J., Owen, R., Macnaghten, P.: Developing a framework for responsible innovation. Res. Policy 42(9), 1568-1580 (2013). https://doi.org/10.1016/j.respol.2013.05.008

25. Tsujimoto, M., Kajikawa, Y., Tomita, J., Matsumoto, Y.: A review of the ecosystem concept towards coherent ecosystem. Technol. Forecast. Soc. Chang. 136, 49-58 (2018). https://doi. org/10.1016/j.techfore.2017.06.032

26. van Geenhuizen, M., Ye, Q.: Responsible innovators: open networks on the way to sustainability transitions. Technol. Forecast. Soc. Chang. 87, 28-40 (2014). https://doi.org/10.1016/ j.techfore.2014.06.001

27. Voegtlin, C., Scherer, A.G.: Responsible innovation and the innovation of responsibility: governing sustainable development in a globalized world. J. Bus. Ethics 143(2), 227-243 (2017). https://doi.org/10.1007/s10551-015-2769-z

28. Von Schomberg, R.: Towards responsible research and innovation in the information and communication technologies and security technologies fields. European Commission-DG Research and Innovation, Luxemburgo (2011). https://doi.org/10.2777/58723

29. Von Schomberg, R.: A vision of responsible innovation. In: Owen, R., J. Bessant and M. Heintz (eds.) Responsible Innovation: Managing the Responsible Emergence of Science and Innovation in Society, pp. 01-26. Wiley, New York (2013). https://doi.org/10.1002/978111 8551424

30. Whittemore, R., Knafl, K.: The integrative review: updated methodology. J. Adv. Nurs. 52(5), 546-553 (2005). https://doi.org/10.1111/j.1365-2648.2005.03621.x 
31. Wiek, A., Foley, R.W., Guston, D.H., Bernstein, M.J.: Broken promises and breaking ground for responsible innovation-intervention research to transform business-as-usual in nanotechnology innovation. Technol. Anal. Strateg. Manag. 28(6), 639-650 (2016). https://doi.org/10. 1080/09537325.2015.1129399

32. Wodzisz, R.: Case Study of R-1234yf refrigerant: implications for the framework for responsible innovation. Sci. Eng. Ethics 21(6), 1413-1433 (2015). https://doi.org/10.1007/s11948014-9612-2 